\title{
- Brasil Respeita o Direito dos Povos Indígenas à Educação Superior? Demanda, oferta e ensaios alternativos em São Gabriel da Cachoeira/AM
}

\author{
Diana de Paula Pellegrini' \\ Elie Ghanem' \\ Antônio Fernandes Góes Neto' \\ 'Universidade de São Paulo (USP), São Paulo/SP - Brasil
}

\begin{abstract}
RESUMO - O Brasil Respeita o Direito dos Povos Indígenas à Educação Superior? Demanda, oferta e ensaios alternativos em São Gabriel da Cachoeira/AM. Abordamos a reivindicação indígena por educação superior no Brasil, um direito ambicionado mas de reconhecimento ausente na lei e na opinião pública. Interpretando essa demanda à luz do direito humano à educação ao longo da vida e na perspectiva da descolonização orientada pelo protagonismo intelectual indígena contemporâneo, traçamos um panorama exploratório das oportunidades de educação superior em São Gabriel da Cachoeira (noroeste amazônico), detendo-nos sobre duas licenciaturas que ensaiam modelos alternativos. Apontamos como o acesso de indígenas gradualmente tensiona a universidade hegemônica, ainda que a oferta, confirmando nossa hipótese, não esteja à altura da significância demográfica e política da demanda dos povos originários.

Palavras-chave: Educação Superior. Direito à Educação. Educação Escolar Indígena. Decolonialidade. Interculturalidade.
\end{abstract}

ABSTRACT - Does Brazil Observe Indigenous Peoples' Right to Higher Education? Demand, supply and alternative initiatives in São Gabriel da Cachoeira, Amazonas. This article addresses the indigenous demand for higher education in Brazil, a right desired but not recognized by law and public opinion. Interpreting it in the light of a universal right to lifelong education, and under a decolonial take guided by contemporary indigenous intellectual protagonism, we trace an exploratory panorama of higher education opportunities for indigenous populations in São Gabriel da Ca- 
O Brasil Respeita o Direito dos Povos Indígenas à Educação Superior?

choeira (northwest Brazilian Amazon) and describe two teacher training courses with alternative practices. The access of indigenous people poses incipient tension to mainstream university models, even though the supply, confirming our hypothesis, does not correspond to the demographic and political relevance of the indigenous peoples' demand.

Keywords: Higher Education. Right to Education. Indigenous Schooling. Decoloniality. Interculturality.

UMBEUSAWA MIRIM - Brasil Urespetari Upitasuka sá Maku Tayara Tayunbueramã Turusu? Tapurandusa, mayewasa tawa supe ${ }^{1}$. Yambeusara kua maku tapurandu sa takuasa rese turusuwa Brasil upé, tarikuwa direito mã tiwa yamã lei upé. Kua yaputaisa yande direito mira ita yakuasawa maye aiku maye yamanduari yande makuita kuiri wara ita, yamukamem maita uiku akuasa turusuwa ike tawa upé (noroeste amazônico), mukui licenciatura resewara aikue ike. Yamukamem maita maku ita tawike merupi universidade takiti amu rupi waitate tiwa tamunhã maye yande maku ita yaputaiwa yawe.

Yupinimã sá: Turusuwa Ukuasa. Yapuderisá Yayunbué. Educação Escolar Indígena. Amúrupisa. Interculturalidade.

WEREKAHSARO - Brasil Di'tá Wiôpehsa Yã'ti Po'terikharã Naã Bu'emhuãnukãsere? Naã ua'sé, naã bu'esé, naã bu'ewãkatisé Yãpã wi'í khãse ${ }^{2}$. A'tore u'kuno po'teri khãra naã bu'emhtãntkãse khãsere a'ti Brasil di'tare, naã uhputu ua'se ni'sa mheõ duhtiri pũrĩpu thonikã mahsãre tuo'kãre yã'mahsĩ heõnu'kõña marĩse ni'kã. Thonikãre mahsũ ku't̃ kahtiro põteorõ bu'ewãkãmahsĩse khãsere thonikã naã poterikhãrã bahsi bu'emhuãnukã tuo'mahsĩ duhtimhtãkãsere yõ'kãre, a'te pahka bu'ese licenciatura wãmetisere yã'kahsano Yãpã wi'ípure pehkasãye poterikhãrãye merã mi'põtoekõ bue'wãkasere. A'tiro naã yã'kahsantko wekãre, po'terikhãra pahkase bu'emhuanukã werã a'te pahkase buese wi'íseripure diásaro wa'kã wesamã naã u'kũ nu'kãhase, naã mahsã ku'rari mahsĩse sã'tisa.

Ni'buhtiasé: Bu'emhuãnukãse. Ni'petirã Bu'e Mahsisãma. Educação Escolar Indígena. Duhtinukãhasé. Interculturalidade.

HATHAMETSA - Brasil Itañeeta Namakaa Nhaa Nawikinai Ikadzeetaakakhetti Nako Naikanami Dalipheena? Lipirikanaa, liodzawaaka nakadaali, nawali matsiadali phaa nalhio Hiipanako, $\mathbf{A M}^{3}$. Wakapa lhie namakaa nhaaha nawikinai ikadzeekatakakhettiapani naka naikanamidali pheenawahipaiteriko, naamakaa tha,metsa karoka naakeeta naanhekani lipirikanaaliko lhiehe ittalikanattiapani riko. Nakaiteka linako lhiapepe matsiadalikani nalhio nhaa nawikinai ikadzeekataakakhettiriko lidoromeka neemaka, wadee namakadawalitaka lhiehe neemakaa,nanhekaa nheette nawapiñeetakaa oophittetsa. Wadzeekata apada wakapakaro ikadzeekataakakhetti rikhitte nakaanamidalipheena Hiipanako, nanakhitte nhaaha dzamada licenciatura kadzoperiaha naamakapidzo. Nattaitakaro nakadzeekataakakawa nhaaha nawikinai hanipapheena namakapidzo nanheekherikhittetsa, likathinaatakaro phaa yaanhekhetti kanakaidali phaa nheette lipirikanaa kadzo nanheekadzo.

Yaakottinai kanakaiperi: Ikadzeetaakakhetti Nako Naikanami Dalipheena. Naamakaa Ikadzeekataakakhetti. Educação Escolar Indígena. Karokaro Apaana Ipiiriri Nanako. Interculturalidade. 
A linha de trabalho que deu origem a este texto se dedica a abordar o seguinte problema gerador: as experiências contemporâneas dos povos indígenas brasileiros no campo da escolarização superam o caráter colonialista das escolas historicamente impostas aos indígenas no Brasil? O mote da superação dos paradigmas colonialistas na educação escolar - e as indagações sobre como alcançá-la - começou a ser escutado na década de 1970, nas mesmas salas de aula que outrora foram implantadas nas terras indígenas como uma estratégia central do projeto da colonização portuguesa e, depois, brasileira.

O movimento que se iniciou nos anos 1970 ganhou força na década seguinte, reivindicando a apropriação e recriação das escolas pelos próprios coletivos de professores e lideranças indígenas, com apoio de aliados da sociedade civil. Enfrentando contínuas adversidades, limitações e contradições, tal frente de atuação tem também originado um corpo de práticas e de pensamento com potencial para contestar os modelos comuns de escola. Na linha de investigações sobre Educação Escolar Indígena do Ceunir - em cujo programa mais amplo se inserem estas reflexões - temos examinado o caso de experiências ousadas, por exemplo com vistas a efetivar a gestão comunitária das escolas (Abbonizio, 2013), levar em consideração línguas, costumes e calendários indígenas (Vieira, 2018), compatibilizar o saber escolar com aspirações endógenas de futuro (Ghanem; Abbonizio, 2012; Pellegrini, 2014), afirmar a autonomia das comunidades diante do padrão das burocracias estatais (Pellegrini et al., 2019; Pellegrini; Ghanem; Góes Neto, 2020) e renovar práticas pedagógicas e epistemológicas, especialmente em face da progressiva ocupação dos cargos de ensino e (timidamente) de gestão pelos próprios pensadores indígenas.

Tendo esse acúmulo como nosso ponto de referência, a presente exploração estende a investigação ao campo da educação superior. A seguir, fundamentamos a defesa do direito de aprendizes e coletivos indígenas a acessarem oportunidades relevantes de formação profissional e de estudos avançados. E, nas seções posteriores, reunimos elementos para indagar, em um contexto amazônico: como esse direito está sendo exigido e cumprido?

\section{Os povos indígenas têm direito ao ensino superior?}

Embora a Declaração Universal dos Direitos Humanos determine que "Todos têm direito à educação", o documento prescreve a gratuidade e a disponibilidade universal apenas aos "estágios elementares e fundamentais" de ensino. Uma vez que a disponibilidade de oportunidades educacionais é condição necessária à observância desse direito humano, o conceito de direito universal parece não se estender ao ensino superior: a Declaração recomenda apenas que esse nível seja acessível em bases não discriminatórias, mas, ao contrário do que estabelece para os níveis básico e técnico, não estipula que o superior deva ser "geralmente disponível". 
O Brasil Respeita o Direito dos Povos Indígenas à Educação Superior?

Embora, mais recentemente, a Declaração Mundial sobre Educação para Todos (Jomtien, Tailândia, 1990) e os documentos internacionais que se seguiram endossem a perspectiva de que a educação começa no nascimento e dura por toda a vida, esse princípio ainda não foi totalmente absorvido pelas peças do direito internacional, nem está sedimentado na opinião pública. A legislação brasileira ecoa essa limitação conceitual, não reconhecendo o acesso aos estudos superiores como parte da realização do direito à educação ${ }^{4}$.

Tal debate é realizado por McCowan (2015), para quem a validade de um direito pode ser uma questão moral que independe do reconhecimento legal, podendo precedê-lo. Defender, dentro destas premissas, que o direito ao ensino superior está coberto pelo direito humano à educação ao longo da vida pode ser uma posição provocativa, uma vez que reenquadra a justificativa para a existência de quaisquer critérios de acesso a vagas (para além de certos requisitos mínimos) ${ }^{5}$ e acentua questões sobre a adequada correspondência da oferta de nível superior a características, necessidades e propósitos pertinentes para todos os aprendizes. Essa ressignificação deslocaria o foco dos esforços de gestão pública em torno do acesso, instando à concepção de sistemas com uma oferta muito diversa e amplamente disponível, flexíveis em tamanho e operação, de modo a expandir ou contrair seguindo a oscilação do número de pessoas que desejem estudar (McCowan, 2015, p. 179).

Mas a pertinência da oferta exigiria também o reconhecimento de que a mera existência de vagas não cumpre o direito à educação, pois as oportunidades educacionais devem ser adequadas não apenas em "disponibilidade" (vagas suficientes) e "acessibilidade" (admissão e frequência sob mecanismos não discriminatórios), mas também na "aceitabilidade" de currículos relevantes e respeitosos, e enfim na "adaptabilidade” das práticas pedagógicas, gerenciais e institucionais de acordo com as necessidades dos alunos. Esses quatro critérios - propostos por Katarina Tomasevski (2004) como indicadores da observância do direito humano à educação - colocam a questão crucial de levar em conta quem são os alunos, e como eles formulam suas próprias necessidades educacionais.

Tais considerações se dão sobre um cenário de expansão global acelerada das taxas de matrícula no ensino superior (Schofer; Meyer, 2005), condicionada porém às desigualdades locais que deixam para trás regiões periféricas e grupos sociais vulneráveis. No Brasil, como em realidades latino-americanas mais amplas, as desigualdades de acesso e adequação são ainda mais graves no que diz respeito aos povos nativos. Isso também porque, mesmo após a independência formal dos países da região, a colonialidade como quadro epistemológico não foi eliminada, definindo ainda a vida das instituições, das relações sociais, da educação, da ciência e do pensamento.

Os teóricos do grupo Modernidade/Colonialidade lançaram luz sobre essa realidade, enunciando uma guinada crucial para o pensamento latino-americano: o "giro colonial" registrado por Ballestrin (2013). Dentre as contribuições desses autores, abraçamos a sugestão 
de Catherine Walsh (2012) de uma abordagem "crítica" do conceito de interculturalidade. Buscando diretrizes mais intelectualmente subversivas para a tarefa de descolonizar "o poder, o saber, o ser e o viver", a autora confere centralidade ao desvelamento do racismo como um organizador de significado social sob a colonialidade, superando assim as limitadas concepções de simetria ou neutralidade intercultural que parecem estar implícitas em noções como as de "tolerância" e "multiculturalismo".

Ao denunciar tais assimetrias epistemológicas constituintes da interculturalidade colonial, essa abordagem enseja a admissão do próprio limite da enunciação não-indígena de caminhos práticos (por mais arrojados que pretendam ser) para os dilemas indígenas contemporâneos. Os alunos e intelectuais "do outro lado" do diálogo intercultural falam em seu próprio nome, e com isso fornecem balizas também para os seus aliados não-indígenas levarem a cabo as críticas continuamente necessárias à colonialidade. Francineia Fontes (2019, p. 222-223), antropóloga do povo Baniwa, pondera:

A presença indígena nas universidades é um assunto que rende muitas discussões e estudos, suscitando 'esperanças' em várias áreas de conhecimentos. A tradição intelectual indígena de ver, pensar, organizar, enxergar o mundo, relacionar, perceber as mudanças do tempo e da sociedade, é o avesso das políticas de conhecimento na universidade, ela está ancorada numa outra epistemologia que não é aquela que aprendemos nas escolas e nas universidades convencionais. Da mesma forma como a ciência, os sistemas de conhecimentos indígenas são complexos, tendo como fios condutores a cosmologia e a cosmopolítica. Eles são transmitidos de maneira organizada como teorias de conhecimento, no espaço e no tempo específico. Apesar da carga de conhecimentos aprendidos no seio de nossas sociedades, nós estudantes indígenas no universo da universidade somos tratados muitas vezes como sujeitos de 'tábula rasa', que estão sempre no polo dos aprendizes, carentes de conceitos e sem epistemologia própria.

Interpretando a demanda indígena por educação superior sob a intersecção das premissas retraçadas até o momento, e descrevendo e avaliando sobre essas bases a oferta local de cursos superiores em São Gabriel da Cachoeira (bacia do Alto Rio Negro, noroeste da Amazônia brasileira, conhecida como "a cidade mais indígena do Brasil"), pretendemos concorrer para a ampliação do conhecimento sobre o acesso dos povos indígenas contemporâneos às oportunidades de ensino superior e sobre o consequente tensionamento gradativo dos modelos hegemônicos de universidade.

\section{Por que enfrentamos essa pergunta?}

A presença do Ceunir em São Gabriel data de 2008, sobretudo realizando pesquisa educacional ${ }^{6}$ em colaboração com escolas indígenas 
O Brasil Respeita o Direito dos Povos Indígenas à Educação Superior?

de educação básica. A sucessão de trabalhos na região tem tomado a forma de um programa de pesquisa mais amplo pautado pelo já mencionado problema fundamental da superação autodirigida da colonialidade na escolarização entre indígenas.

O trabalho de campo correspondente é realizado principalmente nas terras indígenas, em localidades situadas a muitos dias de viagem fluvial a partir da área urbana. Essas "comunidades”, como são regionalmente chamadas, alcançaram uma cobertura razoável de escolas básicas interculturais administradas e financiadas pelos governos municipal (níveis infantil e fundamental) e estadual (nível médio e segunda etapa do fundamental), mas permanecem física e simbolicamente distantes das fontes locais de informação sobre universidades e outras opções de estudo avançado. No entanto, as demandas dos residentes por oportunidades de ensino superior para seus filhos em idade escolar ou recém-formados são enérgicas e recorrentes.

Sentindo a necessidade de iniciar uma abordagem exploratória dos cenários regionais relativos ao ensino superior, propusemo-nos recolher informações para uma caracterização inicial das ofertas locais. Já esperávamos encontrar um cenário com oportunidades insuficientes em relação ao tamanho, qualidade, intensidade e peculiaridades da demanda local; e prevíamos grande predominância (como ocorre em outras regiões brasileiras) de cursos de formação de professores entre as opções oferecidas. Também assumimos a possibilidade de detectar ensaios marginais, e entretanto promissores, em direção a modelos alternativos de ação no ensino superior, rumo à incorporação de práticas educacionais inovadoras e enquadramentos epistemológicos mais radicalmente interculturais.

Desde que os protestos estudantis de 2015-2016 nos campi sulafricanos tornaram inadiável no mundo todo a agenda da descolonização de currículos, práticas e concepções no ensino superior, o desafio de cumprir essa tarefa em diferentes contextos locais ${ }^{7}$ necessita ser subsidiado pela composição de múltiplos repertórios de empiria e reflexão. O exame das mobilizações para a apropriação indígena da educação superior em São Gabriel visa a problematizar e informar os esforços em prol do direito desses grupos à educação superior em nível regional e nacional, dialogando igualmente com esforços semelhantes de muitos outros países na mesma direção.

\section{Os povos indígenas querem ensino superior? Demanda no Brasil e no rio Negro}

São Gabriel da Cachoeira está localizada a 852 km de Manaus, no alto curso do rio Negro, formador do Amazonas. Ali em seu curso superior, a bacia do Negro é coberta por vastas terras indígenas demarcadas contíguas, que em São Gabriel representam $80 \%$ do extenso território municipal, de $109 \mathrm{mil} \mathrm{km}^{2}$. É uma das cidades brasileiras com maior proporção de população indígena, abrigando 23 etnias falantes de 19 idiomas de 4 troncos linguísticos (Cabalzar; Ricardo, 2006). Entre os 
não-indígenas, a maioria é de comerciantes, militares e servidores públicos que vivem com suas famílias no núcleo urbano. Mas mesmo este é habitado em grande parte por indígenas, que representam mais de $76 \%$ dos 46.000 residentes (IBGE, 2020). Cerca de metade dessa cifra vive em mais de 700 comunidades espalhadas pelas terras indígenas, principalmente ao longo das margens dos rios, mas também em assentamentos de floresta profunda, conectados por extensas trilhas aos principais cursos fluviais.

No entanto, a alcunha de "cidade mais indígena do Brasil” não vem simplesmente desse perfil demográfico, mas dos traços expressivos daquilo que a etnologia ameríndia denomina "área etnográfica do Alto Rio Negro”. Trata-se de um complexo sistema regional (Ribeiro, 1995) pelo qual essa mencionada variedade de povos configura refinadas redes de relações e trocas (culturais, econômicas, matrimoniais, linguísticas, ecológicas, sociais, cosmológicas) cuja ancestralidade em termos de "linhagens, tradições intelectuais e sacerdotais elaboradas, formulações explícitas de hierarquia, [e] arquitetura complexa” está na base de uma sugestão de Stephen Hugh-Jones em favor do emprego do conceito de "civilizações amazônicas" (Lasmar; Gordon, 2015).

São Gabriel da Cachoeira funciona como uma capital microrregional para os moradores das terras demarcadas, como também das zonas urbanas e "comunidades" dos dois municípios adjacentes, Barcelos e Santa Isabel do Rio Negro, igualmente abarcados pela bacia hidrográfica do alto Negro.

Lá, foram formados alguns dos mais vigorosos movimentos pelos direitos indígenas do Brasil ${ }^{8}$, no seio das disputas pela Constituição de 1988. Seguiram-se a demarcação das terras e a melhoria relativa das condições de vida. As escolas básicas existentes, antes controladas por igrejas e órgãos tutelares, foram alocadas sob a responsabilidade dos governos municipais e estadual e constitucionalmente obrigadas a respeitar a diversidade cultural e as decisões comunitárias.

Isso exigiu a crescente qualificação e certificação de professores indígenas, muitas vezes recorrendo-se à sua formação em serviço. Assim, a pressão por acesso indígena ao ensino superior surgiu antes mesmo de existirem contingentes significativos de indígenas com a escolaridade básica completa: foi motivada pela necessidade de qualificação de professores indígenas, para o desenvolvimento de projetos de escolarização autônoma e intercultural ligados à concepção coletiva de projetos de futuro. Não se tratava de um cenário singular para a época: a mesma situação era recorrente em várias outras regiões brasileiras que, desde a década de 1970, viam o surgimento das primeiras "licenciaturas interculturais indígenas".

No entanto, no alto rio Negro esse acesso não se iniciou em decorrência de uma ação institucional planejada, mas por fatores aleatórios. Foi por iniciativa pessoal de dois professores que as primeiras opções foram trazidas para a cidade, como relatou uma assessora do movimento indígena à época: 
As duas primeiras graduações que foram disponibilizadas para São Gabriel da Cachoeira de ensino superior, foi no final dos anos 80, [início dos] anos 90, e foi Filosofia e Matemática. Por que essas duas? Porque foram os professores do departamento de Filosofia e do departamento de Matemática que se dispuseram a viajar até São Gabriel da Cachoeira: só por isso. Eu sei porque eu participei de todas as reuniões. [...] Então as lideranças indígenas fizeram esses dois primeiros cursos que ocorreram. O [...] diretor da FOIRN fez Matemática, [um outro líder] fez Filosofia... Enfim, eram essas duas ${ }^{9}$.

Eram cursos oferecidos em etapas, obedecendo às possibilidades dos cronogramas anuais de deslocamento de professores da sede da Universidade Federal do Amazonas (UFAM), em Manaus, para São Gabriel da Cachoeira. Esse formato, com corpos docentes itinerantes que realizam o curso em etapas, sediando-o nas aldeias indígenas ou em cidades próximas de referência, foi depois consagrado nas experiências modelares da Universidade do Estado de Mato Grosso (UNEMAT) a partir de 2001. Consolidou-se como um tipo forte da formação intercultural de professores indígenas e prevaleceu entre as possibilidades de acesso dos indígenas ao ensino superior.

Souza (2003, p. 41) constatou que, em 2003, 75\% dos alunos indígenas no ensino superior frequentavam cursos de formação docente, fossem "diferenciados" ou regulares. A autora explica essa predominância afirmando que "a formação de professores é uma demanda antiga das populações indígenas". Ao lado dessa modalidade de acesso, perduravam as iniciativas de indígenas que disputavam vagas gerais em outros cursos, buscando por conta própria os recursos para custear estudos. Segundo Lima e Barroso (2013, p. 75), a Fundação Nacional do Índio estimou que, em 2004, o número de indígenas matriculados no ensino superior estava entre 1.000 e 1.500 , geralmente em instituições privadas "de qualidade muito duvidosa" (p. 64).

Apesar dessas exceções - grupos de professores e, em outras áreas, poucos pioneiros individuais - o acesso ao ensino superior permanecia em geral distante dos povos nativos. Os avanços de maior escala nesse campo só aconteceram na década de 2000, seja pela criação de cursos interculturais em outras áreas que não a docência, seja pela mais ampla inclusão de indígenas nas vagas regulares do ensino superior ${ }^{10}$. Um marco nesse percurso foi a Lei Estadual no 13.134/2001 do Paraná, caso pioneiro de reserva de vagas universitárias para indígenas no país, amplamente examinado na coletânea de Amaral, Fraga e Rodrigues (2016).

Em 2012, a Lei Federal 12.711, conhecida como "Lei de Cotas", obrigou as universidades federais a reservar vagas para indígenas e negros, na respectiva proporção estadual de residentes para cada categoria étnica. Em 2013, o Ministério da Educação estimou já em 8 mil o número de indígenas matriculados no ensino superior, registrando 26 cursos ativos de formação intercultural de professores indígenas.

A partir desse período, novas leis instituíram ações afirmativas em todo o território nacional, incluindo processos de admissão especí- 
ficos para indígenas e editais públicos para a implementação de novas licenciaturas interculturais. Essas políticas vigoraram por um curto período, até a recente posse de governos declaradamente anti-indígenas. Foi o suficiente para uma multiplicação acelerada do número de matrículas indígenas nos cursos de graduação, cifra que chegou a mais de 56 mil em 2019 - mas manteve desigualdades regionais e, recentemente, vem tendendo à estabilização ${ }^{11}$.

$\mathrm{Na}$ busca de preservar e estender essas incipientes conquistas, tanto a criação de novos cursos diferenciados quanto a ampliação do acesso a cursos regulares são reivindicadas pelos movimentos indígenas como caminhos complementares para atingir o propósito estratégico de formar uma "intelligentsia indígena" (Lima, 2013) com adequada qualificação intercultural.

\section{Elementos da demanda por ensino superior em São Gabriel}

Dos cerca de 250 estabelecimentos de ensino básico em São Gabriel da Cachoeira, a maioria é composta pelas escolas indígenas localizadas nas terras demarcadas: as unidades na área urbana não chegam a $10 \%$ da rede. Em 2018, as matrículas do nível básico somaram 16.833.

Em 2010, entre os residentes com 10 anos ou mais de idade, 4.384 pessoas possuíam o ensino fundamental completo e 4.354 haviam concluído o ensino médio, perfazendo $31 \%$ das pessoas nessa faixa etária. Apenas 740 residentes tinham diplomas de nível superior. Essas taxas de escolaridade, já datadas de 10 anos atrás, não foram atualizadas devido à decisão do governo federal de não realizar o Censo Demográfico de 2020. Há indícios de que os números aumentaram significativamente: dados mais recentes das administrações escolares atestam, por exemplo, o salto de 1.194 pessoas matriculadas nas 16 escolas de ensino médio em 2017 para 2.707 matriculadas em 2018 (Azevedo; Souza, 2020; INEP, 2018).

A decisão de não realizar o Censo de 2020 contribuiu para invisibilizar o importante crescimento demográfico atual da população indígena em território brasileiro - composta de mais de 800 mil indivíduos em 2010, e hoje ultrapassando a marca de 1 milhão de pessoas (Corte..., 2021). Ficou interrompida a regularidade das séries históricas decenais que permitiam detectar e analisar essas evoluções, incluindo o aumento dos anos de estudo. Os povos indígenas no Brasil têm hoje pirâmides etárias de base ampla, refletindo uma rápida recuperação demográfica iniciada na década de 1970 (após séculos de extermínio e depleção populacional) e intensificada a partir da década de 1980. Resultam perfis demográficos em que até $50 \%$ da população têm menos de 18 anos. O horizonte, portanto, é de gradativa pressão para o acesso ao ensino superior por parte de populações que aumentam em números absolutos, prenunciando-se a demanda crescente de pessoal qualificado para uma gestão territorial autônoma e criativa de ambientes sob crescente pressão antrópica ${ }^{12}$. 
O futuro dos territórios e das gerações mais jovens é frequentemente mobilizado como argumento central na reivindicação de "oportunidades de continuar o estudo". Isso é ilustrado pelos apelos registrados durante as visitas (2018-2020) a escolas e comunidades dos povos baniwa e koripako do rio Içana, importante afluente do Negro, nestas notas de campo:

[Um professor] quis saber como preparar formandos fora, para que voltem à comunidade; ou como ter universidade na comunidade para não terem que estudar na cidade.

[Um pai de aluno] perguntou se havia um plano para o ingresso de "jovens aldeados nas universidades" e se a USP, por exemplo, poderia vir à aldeia: "talvez curso de extensão no Rio Negro? Ou propomos para os jovens entrarem lá?".

[Um professor] perguntou como faz para os estudantes irem para a universidade em São Paulo. Respondi que, primeiro, têm que estudar para passar no exame. O capitão Antônio e o ancião Cândido estiveram presentes todo o tempo da reunião.

[Fala de um professor:] “[...] precisamos de políticas públicas para formar nas universidades e trazer aqui. Por exemplo, saúde".

[Fala de um professor:] "Quero seguir estudos na universidade em São Paulo ou Manaus. Em setembro, em São Gabriel, fiz vestibular indígena da Unicamp. Época de rio seco, não dá pra descer sozinho. Distante, precisa comprar 50 litros de gasolina."

[Uma mãe de aluno] queria mais estudo para os filhos: [...] "terminando ensino médio, ficam aqui porque os pais não têm dinheiro para pagar faculdade; você viu a distância de lá [...] remando seria um mês, com rabetinha uma semana e meia, não tem como deixar os filhos estudarem"; "se tiver cursos para trazer para a comunidade para que possam continuar o estudo deles; fazer prova para cá; ir [à zona urbana de] São Gabriel pelo menos".

[Uma egressa da escola] disse ter terminado o ensino médio em 2017, ter filhos, ser casada e querer obter emprego e melhorar a convivência. Disse ser difícil ter recurso para viver e viajar para outras localidades: "teria que ter curso na comunidade próximo para continuar os estudos".

Outras situações demonstraram esse notável apreço pelo assunto. Em 2019, adicionou-se ao cronograma previamente acertado com a comunidade de Canadá, no rio Ayari (afluente do Içana), uma conversa sobre as opções disponíveis naquele ano para estudos universitários em São Gabriel e em outras cidades, e sobre as formas de preparação para o vestibular. No mesmo ano, as equipes docentes de quatro comunidades assinaram cartas demandando a criação de mecanismos de admissão especial de indígenas na pós-graduação da Faculdade de Educação da Universidade de São Paulo. Em 2020, grupos de jovens e seus familiares prepararam documentos dirigidos à reitoria da mesma universidade, solicitando providências para a realização de um vestibular indígena.

A existência de oportunidades locais é particularmente importante porque esses povos vivem em áreas remotas, separadas até do nú- 
cleo urbano de São Gabriel por árduas viagens fluviais. Lima e Barroso (2013) destacam que os longos deslocamentos de indígenas para cursar faculdade são uma situação recorrente em todas as regiões do Brasil, muitas vezes percorrendo distâncias interestaduais e envolvendo famílias inteiras.

Além das características geográficas e demográficas, as peculiaridades locais da demanda educacional também se relacionam à história e às necessidades, preferências e intenções dos grupos nativos.

Um projeto alternativo que veio a ser concebido no alto rio Negro tentou modelar cursos de graduação que respondessem a esses aspectos, mas não foi realizado devido à descontinuidade das negociações por parte do governo federal. Por prever o financiamento dos Ministérios da Educação e da Tecnologia mas a administração diretamente realizada pelos representantes indígenas e suas organizações parceiras, a proposta (provisoriamente chamada por vários nomes, principalmente "Instituto dos Conhecimentos Indígenas e Pesquisa do Rio Negro" e, mais tarde, simplesmente "Universidade Indígena do Rio Negro", UIRN) foi descrita por McCowan (2016, p. 212-214) como o caso exemplar de uma solução institucional "liminar" de ensino superior alternativo - ou seja, que busca conciliar as vantagens de reconhecimento oficial e financiamento estável, desfrutadas por experiências situadas "dentro do sistema mainstream", com aquelas de maior autonomia e relevância local, que distinguem as iniciativas que fizeram o "êxodo do mainstream".

Embora as mudanças dramáticas no cenário político brasileiro tenham impedido a criação da Universidade Indígena do Rio Negro, o estado detalhado de seu planejamento - baseado em um amplo processo participativo de 2009 a 2014 - legou diretrizes ousadas, que descrevem particularidades de uma demanda local por ensino superior intensamente informada pelo histórico recente da região na experimentação de projetos de educação autônoma e intercultural, nas escolas das comunidades.

As decisões coletivas foram compiladas na forma de duas listas breves: "O que queremos" e "O que não queremos". Segundo o documento, queria-se uma educação superior "autônoma", com ampla cobertura regional e que facultasse às pessoas graduadas trabalhar em suas próprias comunidades, para melhorar as condições de vida e administrar os recursos locais de maneira sustentável; também se desejavam cursos com diálogo intercultural equilibrado e combinação de conhecimentos indígenas e não indígenas; aprendizagem interdisciplinar centrada na pesquisa; desenho institucional aberto e flexível; calendários com adequação microrregional; parceria e intercâmbio com universidades convencionais; certificação oficial; e atenção às áreas de Educação, Saúde e Meio Ambiente. O que não queriam: estruturas burocráticas; cursos monolíngues com predominância de conhecimento científico; replicação de cursos comuns de ensino superior; e competir com outras alternativas de acesso indígena, como diplomas interculturais e vestibulares específicos ${ }^{13}$. 


\section{Oferta: é possível frequentar o ensino superior sendo indígena em São Gabriel?}

Como tem sido atendida a demanda até aqui exposta? Embora Mato (2015, p. 36-37) proponha outros ângulos de classificação para a experiência latino-americana mais ampla, sintetiza-se aqui a variedade de distribuições pelas quais a literatura brasileira recente identifica as modalidades que a presença indígena no ensino superior tem assumido no país:

a) "Ação afirmativa”, os dispositivos jurídicos, administrativos e políticos de inclusão de indivíduos: cotas para as vagas existentes ou criação de vagas adicionais em cursos regulares, acessíveis por concurso específico e acompanhadas de programas de bolsa e políticas de permanência estudantil. O ingresso de alunos indígenas nas instituições de ensino superior acarreta poucas adaptações, mas sua presença provoca o microtensionamento dos formatos hegemônicos.

b) Cursos interculturais, na forma de programas especiais em universidades regulares, geralmente seguindo o modelo pioneiro e ainda predominante das licenciaturas indígenas, caracterizado por: influência comunitária e discente em sua concepção e operação; propostas curriculares interculturais e interdisciplinares, comumente com aprendizagem baseada em pesquisa, projetos, temas contextuais ou problemas; calendários modulares, adequados às sazonalidades locais; membros do corpo docente com sensibilidade intercultural e uma atitude respeitosa e flexível; e formatos institucionais "realizados dentro do sistema mainstream", da mesma maneira que os cursos da primeira modalidade - mas estimulando mais inovação e causando maior tensão ao modelo. Nesse formato, ainda são raros os cursos em outras áreas que não sejam a formação de professores: bons exemplos vêm do Instituto Insikiran de Formação Superior Indígena, ativo desde 2001 na Universidade Federal de Roraima, que oferece três graduações interculturais (além da Licenciatura, há cursos de Gestão Territorial Indígena e de Gestão em Saúde Coletiva Indígena).

c) Institutos ou universidades indígenas, idealizados e administrados por coletivos indígenas com o apoio de aliados, seja adotando formatos "liminares" em relação ao sistema de ensino superior, como a Universidade da Floresta ${ }^{14}$ e a Universidade Indígena do Rio Negro, seja radicalmente afastados desse sistema, como a Universidade Intercultural Indígena da Aldeia Maracanã, no Rio de Janeiro (McCowan, 2016, p. 208-209). Têm mostrado frágeis perspectivas de sobrevivência, o que não diminui a importância de avaliar os aprendizados, os materiais derivados e os saldos de mobilização deixados por esses "fracassos instrutivos"15, nem reduz a pertinência de novos ensaios futuros.

Mesmo na primeira modalidade, que não propõe diretamente modelos alternativos, a presença indígena na universidade tem efei- 
tos propagadores que pressionam cumulativamente na direção de “[...] avanzar en transformaciones de las universidades y otras IES convencionales hacia la incorporación de conocimientos, idiomas, docentes y estudiantes de los pueblos indígenas (lo que se suele denominar interculturalización de la educación superior)" (Mato, 2015, p. 36, grifos do autor).

A materialização de diferentes soluções para a promoção do acesso dos indígenas aos cursos de graduação e pós-graduação $0^{16}$ no Brasil, bem como a sua incipiente admissão aos cargos de docência e gestão nesses níveis de estudo, têm levado a experiências pedagógicas inovadoras situadas, e a mudanças em alguns aspectos administrativos circunscritos. Oliveira (2020) relata como, em Amajari, Roraima $(750 \mathrm{~km}$ a nordeste de São Gabriel), o simples recebimento dos jovens macuxi habitantes das terras indígenas da região nas dependências e na esfera institucional do Instituto Federal de Educação levou a revisões nas áreas de uso comum, procedimentos de gestão, práticas de conhecimento e relações pessoais. As medidas tomadas por equipes sensíveis sob o imperativo de respeitar e apoiar as particularidades dos estudantes indígenas para concluir seus estudos tensionam progressivamente as continuidades coloniais que marcam o modelo universitário.

Adotando, portanto, a dupla atitude de sustentar objetivos audaciosos e ao mesmo tempo valorizar avanços táticos, passamos à consideração das informações encontradas sobre a oferta de ensino superior aos povos indígenas em São Gabriel da Cachoeira.

\section{Oportunidades de ensino superior em São Gabriel: dados oficiais e institucionais}

Os dados solicitados diretamente às instituições de ensino superior, bem como os dados governamentais disponibilizados pelo Instituto Nacional de Estudos e Pesquisas Educacionais (INEP), mostraram-se de difícil acesso e validação.

Em 2017 e 2018, entramos em contato com as duas universidades públicas presentes em São Gabriel da Cachoeira: a Universidade Federal do Amazonas (UFAM) e a Universidade do Estado do Amazonas (UEA). As respostas da UEA informaram sobre quatro cursos: Bacharelado em Educação Física, iniciado em 2015; Licenciatura em Letras-Língua Portuguesa e Licenciatura em Ciências Biológicas, ambos iniciados em 2016; e Tecnólogo em Gestão Comercial, iniciado em 2017. Cada um oferecia 40 vagas anuais. Apenas o curso de Licenciatura em Ciências Biológicas era presencial, em módulos.

Em 2019, recolhemos oralmente a informação do aumento da oferta de cursos por essa instituição, incluindo a expansão das opções presenciais modulares. Também tivemos reiterada notícia de que a UEA já havia, em épocas anteriores, sediado outras ofertas locais de formação docente por meio do Plano Nacional de Formação de Professores da Educação Básica (Parfor, do Ministério da Educação), certificando 
O Brasil Respeita o Direito dos Povos Indígenas à Educação Superior?

muitos dos professores "especialistas" (de Espanhol, Matemática, Artes, Filosofia etc.) que hoje trabalham nas escolas básicas das comunidades.

No caso da UFAM, as respostas oficiais à época indicaram apenas o curso Licenciatura Indígena Políticas Educacionais e Desenvolvimento Sustentável. Mas nossas informações de campo também registravam a existência do programa Licenciatura Formação de Professores Indígenas, um formato que a UFAM opera desde 2007 em outras regiões do interior do Amazonas e que trouxe para São Gabriel em 2015.

Da administração das duas instituições universitárias não obtivemos outros dados além desses, apesar de pedidos de detalhamento sobre o número e perfil dos alunos, currículos e programas disciplinares, cargas de atividade, línguas de instrução, atores envolvidos na concepção e governança dos cursos e destinos profissionais de ex-alunos.

Buscando complementação em fontes oficiais, constatamos que os mais recentes microdados governamentais (INEP, 2021) informam a existência de oito cursos de nível superior sediados em São Gabriel em 2019, dos quais cinco seriam de formação de professores. Dois deles são nomeados como carreiras "interculturais indígenas", mas não são os mesmos dois acima mencionados, uma vez que os nomes dos cursos e das instituições prestadoras não coincidem: o primeiro é registrado genericamente como "Licenciatura Intercultural Indígena" ${ }^{17}$ e o segundo é um curso de Pedagogia Indígena Intercultural oferecido pela UEA ${ }^{18}$. Os outros três cursos de formação de professores são Matemática, Língua Portuguesa e Ciências Biológicas, também ministrados pela UEA. Além desses, há o bacharelado em Odontologia oferecido por uma faculdade privada; e dois cursos de tecnólogo da UEA, em Gestão Pública e Gestão Comercial. O conjunto de dados exibe 494 matrículas em 2019, mas não informa nenhuma matrícula ou admissão para a maioria dos cursos listados naquele ano, concentrando 428 daquele total no curso particular de Odontologia.

Os dados oficiais e as informações fornecidas pelas próprias instituições não condizem inteiramente com a nossa observação direta, que detecta uma ligeira expansão das opções nos últimos anos em termos de áreas e carreiras. Os parcos fatos permitem, no entanto, retratar a estreiteza das oportunidades disponíveis, com pouca variedade de modalidades oferecidas e (dada a descontinuação da UIRN) a existência de alternativas de educação superior apenas do tipo que permanece dentro dos modelos institucionais convencionais.

Além disso, as medidas de interiorização territorial, que sustentam, na administração universitária, a chegada desses cursos à cidade de São Gabriel, são altamente dependentes de arranjos circunstanciais e de oscilações quanto a pessoal e recursos financeiros, fragilidades coincidentes com as das políticas federais que outrora impulsionaram a formação de professores indígenas no Brasil. A chegada de um novo curso à cidade não garante, para os anos seguintes, a abertura contínua de novas turmas. As modalidades de oferta predominantes consistem em cursos não interculturais, a distância ou presenciais modulares, estes obedecendo aos calendários da itinerância de equipes docentes pe- 
los diversos campi avançados do estado do Amazonas. Como resultado dessa grande flutuação nas oportunidades existentes de ano a ano, a trajetória dos indígenas dispostos a estudar nesse nível de ensino acaba sendo determinada menos por planos e escolhas de carreira e mais pelas oportunidades disponíveis a cada momento, vistas como possibilidades a serem aproveitadas. Alguns desses aspectos serão ilustrados por entrevistas com alunos e ex-alunos.

Pelos critérios de Tomasevski para avaliar a observância do direito à educação, este é um panorama de baixa disponibilidade de cursos, tanto em número quanto em diversidade; e com desafios importantes apontados de forma consistente no que diz respeito ao acesso, como se verá a seguir.

No entanto, tínhamos informações, por meio de nossa convivência com equipes de professores e professoras do ensino básico, sobre práticas alternativas ocorridas nas duas licenciaturas indígenas realizadas pela UFAM. De fato, as entrevistas indicaram que os dois cursos abrigaram práticas mais tendencialmente inovadoras e interculturais que, embora tímidas, resultam em índices significativos de adaptabilidade e aceitabilidade por parte dos alunos e ex-alunos indígenas, como também será explorado a seguir. Esses parecem ser passos em direção a apropriações mais subversivas do ensino superior pelos professores e intelectuais indígenas do alto rio Negro.

\section{As licenciaturas interculturais podem fomentar modelos alternativos?}

Os dois cursos de formação de professores presentes em São Gabriel que seguiam o consolidado modelo brasileiro para as licenciaturas interculturais indígenas - concepção e governança comunitária, currículos inovadores, calendários modulares, valorização de línguas nativas, docentes com sensibilidade intercultural e tentativas de maior flexibilidade gerencial - eram a Licenciatura Indígena Políticas Educacionais e Desenvolvimento Sustentável, oferecida pelo Instituto de Filosofia, Humanidades e Ciências Sociais, IFCHS, e a Licenciatura Formação de Professores Indígenas, pela Faculdade de Educação, FACED, ambas unidades da UFAM.

O curso da FACED (com apenas uma turma até o momento, 20152021) ocorreu no núcleo urbano, enquanto o curso do IFCHS (duas turmas concluídas, 2009-2013 e 2014-2018 para o polo Baniwa, com pouca variação de anos para os outros dois polos) ocorreram em três "polos linguístico-territoriais" (Baniwa, Tukano e Yẽgatu ${ }^{19}$ ) dentro das terras indígenas.

Ambos os cursos buscaram alcançar condições máximas de acesso, levando em consideração as peculiaridades geográficas e sociais, com financiamento para transporte e alimentação, empréstimo de equipamentos e algumas bolsas oferecidas - embora conseguindo soluções limitadas e intermitentes, no escopo dos recursos existentes. Para os entrevistados, a ausência dessas condições nas outras opções de 
O Brasil Respeita o Direito dos Povos Indígenas à Educação Superior?

curso foi um motivo determinante para a escolha por cursar as licenciaturas interculturais.

Eles consideraram que o conteúdo atendeu às suas necessidades, exceto por uma veemente observação de um dos entrevistados, que sente falta de ter cursado "as disciplinas dos cursos regulares de graduação” além do currículo com temática local e baseado em pesquisas. Os entrevistados também referiram o uso de linguagens e métodos de ensino compreensíveis.

Ambos os cursos, mesmo com políticas linguísticas distintas, promoveram práticas de valorização das línguas nativas, incluindo a tradução sistemática ou frequente das explicações das aulas em português, em sistema de revezamento entre os alunos bilíngues. Os procedimentos de avaliação foram considerados adequados, transcendendo a restrição do usual enfoque restrito a mensurações finais de retenção de informações. Atitudes flexíveis e respeitosas foram relatadas por parte dos docentes não indígenas em relação ao contexto local, uma opinião assim resumida: "Diante dessa pluralidade étnica e linguística, para os professores foi um desafio em que fizeram o possível para repassar informações, mudando metodologias de ensino e adaptando-se às necessidades da turma”.

\section{Licenciatura Indígena Políticas Educacionais e Desenvolvimento Sustentável}

Durante nossa visita às comunidades do Içana em 2018, um professor egresso afirmou que essa licenciatura oferecida pelo IFCHS era "uma das conquistas do movimento indígena para valorizar o conhecimento tradicional”. Com efeito, a iniciativa foi marcada desde o início pela influência das associações indígenas, formando-se um Conselho Universitário Assessor e Deliberativo do Curso composto por FOIRN, UFAM, Fundação Nacional do Índio, secretarias Municipal e Estadual de Educação, representantes discentes, coordenadores indígenas não discentes das turmas Baniwa, Tukano e Yẽgatu, lideranças tradicionais e representantes docentes (Curso..., 2021).

Os dois egressos entrevistados, ambos jovens do povo baniwa, um deles integrante da primeira turma e o outro, da segunda (únicas realizadas até o momento, pois a terceira turma foi selecionada em 2019 mas não iniciou as atividades), informaram que o curso se deu em etapas, sempre durante as férias escolares (janeiro e julho), de forma a acomodar os calendários profissionais de uma maioria de alunos e alunas que já lecionavam. Um entrevistado, porém, considerou a duração das etapas insuficiente para os temas estudados.

As atividades do curso foram realizadas simultaneamente em três comunidades que funcionavam como polos linguístico-territoriais, distribuídas de maneira a cobrir, em conjunto, as extensas terras indígenas da região. Os entrevistados relataram que, no polo Baniwa (sediado em Tunuí Cachoeira, médio Içana), as etapas às vezes eram transfe- 
ridas para outra comunidade, mais abaixo no curso do rio, facilitando o transporte fluvial nos períodos de seca. Mesmo assim, o curso ainda ficou longe das comunidades de origem de alguns alunos, disse um entrevistado, já que estas se encontram dispersas por uma grande área.

A distribuição em comunidades-polo trouxe vantagens inequívocas de convivência e socialização e favoreceu a frequência de quem não poderia custear longas estadias na cidade (ou as temeria para seus filhos jovens). Como desvantagem, trouxe pouca oportunidade de treinar o uso do português e de aprender os modos do mundo não indígena em geral, o que também era esperado. Além disso, foi necessário lidar com infraestrutura precária, pois as aldeias não tinham internet e eletricidade (esta última geralmente depende de geradores a diesel que funcionam por poucas horas diárias, usualmente ao cair da noite). Não foram fornecidos equipamentos e treinamento de informática aos alunos, embora as atividades exigissem o seu manuseio. Os professores traziam materiais impressos, também criando e imprimindo outros no local. Eram fornecidas refeições mas não hospedagem. Os que vinham de outras aldeias eram acomodados na escola, na igreja, em casas vazias ou com familiares.

O português era usado junto com o idioma de cada polo, e a tradução oral sistemática era realizada pelos alunos bilíngues em revezamento $^{20}$. A produção em línguas nativas, incluindo vídeos ${ }^{21}$, recursos didáticos e relatórios de pesquisa, era altamente incentivada. No entanto, alguns alunos ainda tinham dificuldade para falar, entender e escrever em português, motivo apontado pelos entrevistados para alguns de seus colegas quererem desistir.

Empregava-se um sistema de "currículo pós-feito", pelo qual os temas de ensino eram escolhidos para cada turma a partir do seu conjunto de interesses, em vez de haver uma definição preconcebida pelos organizadores do curso. Em seguida, os temas eram abordados em termos de "problemáticas".

Os métodos de avaliação foram considerados compatíveis com essa perspectiva, compreendendo também a autoavaliação dos alunos. Um membro do corpo docente informou à mídia (Sem Aula..., 2019) que as bancas de avaliação dos trabalhos finais dos alunos incluíam "conhecedores indígenas" como avaliadores ao lado de acadêmicos convencionais, e as apresentações podiam ser realizadas na língua materna dos alunos - medidas coerentes com o acolhimento e valorização das perspectivas e saberes indígenas.

Ambos os respondentes consideraram sua experiência no curso satisfatória. Eles informaram resultados positivos em termos de autoestima, reconhecimento comunitário e familiar, interação com os pares, melhoria da prática profissional, diversão, satisfação e utilidade das contribuições para suas comunidades ${ }^{22}$. Ambos mencionaram possibilidades de inserção no mercado de trabalho, mas um deles observou que a ausência das disciplinas convencionais limitava as chances de emprego, além de furtar aos estudantes as possíveis contribuições dessas disciplinas ao exercício profissional. 
O Brasil Respeita o Direito dos Povos Indígenas à Educação Superior?

\section{Licenciatura Formação de Professores Indígenas}

O curso da FACED era coordenado por um dos indígenas pioneiros na conquista de diplomas de ensino superior, hoje ele mesmo professor universitário ${ }^{23}$. Entrevistamos duas alunas, dos povos baré e tukano, que frequentaram a única turma aberta até o momento (2015-2021) em áreas de especialização distintas: "Ciências Exatas e Biológicas" e "Letras e Artes".

De acordo com uma delas, houve, antes do início das aulas, em 2015, um "Seminário de Implementação" com a participação de lideranças indígenas, representantes do governo, coordenação do curso e instituições parceiras. O grupo se comprometeu a buscar formas de atender às necessidades dos alunos e minimizar as dificuldades nos aspectos do estudo e da permanência.

As aulas também seguiram um calendário modular mas, à diferença da licenciatura do IFCHS, as etapas foram ministradas na área urbana, em instalações cedidas pelo Instituto Federal de Educação do Amazonas (IFAM). Essa localização favoreceu os muitos indígenas que vivem na cidade, mas também atraiu alguns dos que vivem em comunidades distantes. Como o IFAM não está localizado no centro comercial de São Gabriel, a Secretaria de Educação da cidade ofereceu transporte de ônibus do centro ao câmpus. O IFAM também ofereceu acomodações, mas uma entrevistada afirmou que os alunos preferiam ficar com parentes ou em casas alugadas. No início havia um orçamento para alimentação, depois interrompido por cortes de verbas. Os alunos puderam usar um laptop e uma impressora, também emprestados pelo IFAM. Os professores forneciam apostilas para cada matéria.

As etapas foram programadas de acordo com os calendários de itinerância dos grupos docentes, variáveis, e a data de início de cada módulo era comunicada com pouca antecedência. Isso criou empecilhos de planejamento para os alunos que trabalhavam, e precisavam encontrar (e pagar) substitutos para cobri-los quando as semanas de curso coincidiam com períodos letivos das escolas básicas onde lecionavam. As aulas eram em português, mas frequentemente eram feitas apresentações em línguas indígenas, traduzidas para o português em seguida, uma vez que a diversidade linguística era alta. Os alunos sentiam liberdade e incentivo para se expressarem tanto em português quanto em suas línguas maternas. Uma aluna que fala apenas português disse ter tido dificuldades de comunicação no princípio, logo superadas.

Não foi trabalhada especificamente somente uma língua indígena, porque a turma é formada por diversos povos (Tukano, Tariano, Piratapuia, Baré, Baniwa, Kubeo, Tuyuka, Werekena, Wanano, Karapanã, Ye’bámahsã, Dessano) e as línguas que a turma domina são: Tukano, Baniwa, Nheengatu, Tuyuka, Kubeo e a língua pátria (Entrevista com estudante).

Os instrumentos de avaliação eram realizados por alunos e professores, ao final de cada etapa, e incluíam opinar a respeito "da logística, dos conteúdos, da coordenação do curso, se teve a valorização da 
cultura, se os conteúdos estudados proporcionaram melhoria da comunidade, e [se havia] sugestão", revelando-se preocupação com alguns dos aspectos que aqui têm sido chamados, conforme a terminologia de Tomasevski, de "adaptabilidade" e "aceitabilidade". O trabalho final de uma aluna registrou e analisou atividades que ela e uma colega experimentaram em uma escola pública de ensino fundamental da cidade, envolvendo estratégias pedagógicas para manipular objetos naturais e da arte local - sementes, cestos e pequenos remos de madeira - como materiais concretos para a alfabetização matemática entre crianças indígenas urbanas.

\section{Significados das duas experiências}

Em termos de formato institucional, os cursos descritos enquadram-se no tipo de experiência alternativa de ensino superior cujo formato permanece "dentro do sistema mainstream", na medida em que, tendo sido criados como programas especiais em universidades regulares, são financiados pelo governo federal ou estadual e operam dentro de seus marcos institucionais. Contudo os recursos públicos destinados às licenciaturas indígenas no Brasil, além de insuficientes, não se solidificaram em linhas de financiamento estáveis ou duradouras, sendo normalmente alocados por meio de editais públicos pontuais (como é o caso de pelo menos um desses dois cursos) e, assim, permanecendo altamente dependentes das oscilações da conjuntura política nacional - que adere cada vez mais às diretrizes neoliberais de redução da presença do Estado, e dá cada vez mais espaço a forças regressivas com um programa anti-indígena explícito.

Os funcionários e alunos dos cursos, portanto, sustentam lutas contínuas nas esferas internas e externas para manter vivas suas respectivas visões inovadoras em face das "forças centrípetas" (McCowan, 2016, p. 207) por meio das quais os padrões burocráticos e as culturas pedagógicas estabelecidas exercem pressão para arrastar essas práticas de volta para a "norma".

O curso do IFCHS enfrenta ameaças à sua própria continuação. A segunda turma concluiu as atividades em 2018, mas os alunos ainda aguardam a emissão dos diplomas, pois a adoção de um "currículo pósfeito" para cada polo linguístico-territorial gerou incompatibilidades imprevistas entre os históricos escolares e os procedimentos oficiais de certificação. A terceira turma, por sua vez, foi matriculada no início de 2019, mas nunca começou, pois o financiamento federal foi interrompido e a universidade não conseguiu absorver os custos do programa em seu orçamento ordinário (Sem Aula..., 2019).

Ambos os cursos incluem formas de participação indígena na formulação ou implementação de suas propostas e demonstram ímpeto para inovar, em aspectos como valorizar o convívio e conceber modos de avaliação mais amplos e pertinentes, que superem o escopo excessivamente limitado desse conceito no contexto escolar (Ghanem, 2006). 
O Brasil Respeita o Direito dos Povos Indígenas à Educação Superior?

Nos dois casos, buscaram-se confrontar pilares do modelo estabelecido para a educação superior, como por exemplo: a deslegitimação que o conhecimento científico opera sobre o tradicional e o experiencial; os currículos fixos, concentrados em cânones supostamente universais; as pedagogias autoritárias e excessivamente centradas na exposição verbal de informações; a titulação acadêmica como critério exclusivo de expertise; o foco exclusivo sobre a atividade de ensino, em detrimento de necessidades pessoais e comunitárias de aprendizagem; os calendários e horários letivos padronizados; e as burocracias homogeneizantes, que ignoram peculiaridades logísticas e preferências locais. Na mesma direção, o alto estatuto conferido às línguas e saberes indígenas indicou uma disposição para práticas inter-epistemológicas mais simétricas.

As deficiências ecoam as de outros contextos que enfrentam desafios semelhantes ao inovar, ora relacionadas à insuficiência ou ambiguidade da solução que apenas adiciona "temas indígenas" aos currículos $^{24}$, ora ao despreparo sentido pelas equipes de docentes e administradores ao conceber e operacionalizar inovações educacionais e pedagogias descoloniais ${ }^{25}$. Na experiência dos cursos interculturais em São Gabriel, detecta-se o desejo dos professores de encontrar formas práticas de concretização desses horizontes, e verifica-se grande aceitação por parte de alunos e comunidades quando emergem propostas experimentais nesse sentido.

\section{Outras oportunidades existentes: faculdades privadas, mudanças de cidade}

O interesse da população do alto rio Negro pelo ensino superior não passa despercebido aos grandes conglomerados comerciais de educação superior ${ }^{26}$. A UNIP (Universidade Paulista) abriu uma filial em São Gabriel da Cachoeira, oferecendo uma ampla lista de cursos semipresenciais e a distância, com mensalidades relativamente acessíveis.

As instituições públicas também tomaram outras medidas. Atestando a efetiva demanda local pelo ingresso em seus cursos, a Universidade Federal de São Carlos (UFSCar) e a Universidade Estadual de Campinas (Unicamp), ambas localizadas a mais de 3.200 quilômetros de distância de São Gabriel, começaram em 2019 a aplicar suas provas de vestibular indígena diferenciado na sede do município. Naquele ano, 487 candidatos se inscreveram na cidade para o Vestibular Indígena da UFSCar - espantosos $41 \%$ do total nacional de candidatos indígenas da prova, enquanto os demais 59\% fizeram o exame distribuídos pelas capitais Manaus (283 candidatos), Recife (246) ou São Paulo (167) (cf. UFSCar, 2019).

Paralelamente a essas iniciativas, alguns encontram a possibilidade de sair da cidade para continuar os estudos ${ }^{27}$. Enquanto um professor baniwa formado em Brasília era admirado em 2012 como pertencente ainda a uma geração de pioneiros, nos anos seguintes cada vez mais jovens conquistaram vagas em universidades federais pela Lei de Cotas, 
instalando moradia temporária em outras regiões do país. Os exames locais para admissão de indígenas na UFSCar e na Unicamp vêm estabelecendo, ultimamente, um pequeno fluxo anual dessas saídas.

E, tendo em vista a insuficiência quantitativa das políticas implementadas, também aquelas trajetórias de estudo inteiramente baseadas em redes de solidariedade e alto esforço pessoal, que prevaleciam na década de 1970, permaneceram comuns até hoje: em 2018, conhecemos em São Paulo um jovem baniwa oriundo de uma comunidade muito remota da bacia do Içana, vindo por conta própria para estudar Enfermagem em uma faculdade particular, com algum apoio da igreja católica. Havia trazido esposa e filha, e trabalhavam vendendo pães caseiros para custear parcialmente a estadia de 4 anos na cidade, onde tiveram seu segundo filho.

\section{Conclusões}

Qual é o melhor formato para cumprir o direito indígena de acesso à educação de terceiro grau? Embora cobrindo ainda poucas vagas, as oportunidades existentes variam na forma: seja realizando-se um curso em etapas na própria aldeia ou bem perto dela, seja transferindose para cidades maiores e imergindo no ambiente dos campi universitários (cursando programas interculturais especiais ou ocupando vagas regulares por meio de processos especiais de admissão), seja ainda buscando-se assegurar individualmente as condições de admissão e permanência para cursar trajetórias de estudo convencionais - sem falar na participação em potenciais universidades indígenas autônomas. As trilhas disponíveis implicam em objetivos, caminhos e resultados diversos e complementares, correspondendo aos variados conjuntos de necessidades, condições e propósitos que os povos indígenas no Brasil formulam para a sua própria presença na educação superior. O panorama gabrielense, nisso emblemático das realidades nacionais mais amplas, reafirma a demanda por uma oferta ampla e diversa, essencial para a plena realização do direito das pessoas indígenas a acessar esse nível de estudos, bem como para o atendimento das aspirações educacionais coletivas de seus movimentos e entidades representativas.

No caso do alto rio Negro, as informações sobre a expressiva demanda indígena potencial e manifesta por educação superior foram interpretadas nos marcos de um direito humano, de valor intrínseco ao longo da vida e de importância instrumental estratégica para grupos desfavorecidos. Diante dessa demanda, o panorama exploratório das ofertas locais de educação superior esboça um cenário de oportunidades estreitas, flutuantes de ano a ano e incompatíveis com o tamanho, a qualidade, a intensidade, a peculiaridade e o significado cultural e político da demanda indígena regional por esse nível de estudos.

No entanto, a entrada incipiente das pautas e dos próprios estudantes indígenas no ambiente das instituições de ensino teve o potencial de desequilibrar modos cristalizados de concepção e operação. As informações recolhidas confirmaram o pressuposto de que os cursos 
O Brasil Respeita o Direito dos Povos Indígenas à Educação Superior?

de formação docente prevalecem entre as opções disponíveis. Dentre os que se configuram como licenciaturas interculturais, certas experiências circunscritas de ação intercultural voltada para a descolonização (muitas vezes confrontando procedimentos padronizados) forneceram bases práticas para criticar e aprimorar soluções.

A oferta descrita parece notadamente distante de atender às demandas coletivas compiladas em torno do projeto da UIRN, mencionadas acima, principalmente as metas de uma ampla cobertura regional e da criação de outros cursos (além da formação docente) que permitam trabalhar nas comunidades. No entanto, os experimentos das duas licenciaturas da UFAM no sentido de praticar o diálogo intercultural, combinando saberes indígenas e não indígenas, instanciando a aprendizagem interdisciplinar centrada na pesquisa, buscando um desenho institucional mais aberto e flexível e concebendo calendários com adequação microrregional, lançou bases para avanços futuros, especialmente tendo em vista o distante cumprimento da meta de uma educação superior indígena "autônoma", qualificação repetidamente postulada naquela compilação.

Na mesma lista de demandas, a afirmação de que as associações indígenas não queriam que sua universidade "replicasse cursos comuns" nem "competisse com outras alternativas de acesso indígena" é um indício de que essas opções devem ser mantidas abertas, e complementadas - não substituídas - pelas alternativas mais interculturais cuja criação o movimento reivindicava.

Parcerias e intercâmbios dos movimentos indígenas com universidades convencionais, que também são solicitadas na compilação de demandas, já demonstraram ser cruciais para a criação das ofertas de ensino superior existentes até o momento no alto rio Negro, constituindo portanto uma perspectiva promissora de atuação conjunta em termos de planejamento, pesquisa, reflexão e experimentação.

As lideranças indígenas, assim como seus apoiadores, têm justificado predominantemente a demanda dos povos indígenas pelo ensino superior com base em sua importância na formação de professores capazes de promover projetos endógenos de educação básica, ou na formação de lideranças e profissionais para a gestão territorial autônoma e enunciação de projetos coletivos, ou ainda no estabelecimento de relações mais simétricas com as matrizes culturais e epistemológicas dominantes.

Lima (2013, p. 24) detecta que gerações de intelectuais indígenas interculturalmente proficientes vêm recentemente se formando em trajetórias de conciliação entre o ensino universitário convencional e as lições do intenso ativismo em movimentos e associações indígenas, buscando, na academia como na disputa política, formular análises e soluções que enraízem e ampliem conceitos a partir de dentro de suas próprias tradições de pensamento. A crescente e relevante produção científica e didática de professores, lideranças e pesquisadores indígenas do alto rio Negro em áreas como Educação, Antropologia e Linguís- 
tica exemplifica esse fenômeno, que tem ocorrência no contexto geral dos grupos indígenas brasileiros e latino-americanos. Essa empresa pede originalidade intelectual:

Para começar, nós indígenas temos que estar cientes de que a escola e a universidade não são espaços próprios de produção de pensamento e práticas indígenas. Sendo assim, não formará operadores do pensamento indígena, tais como os pajés, estes especialistas são vitais para as sociedades indígenas, possuindo o papel de produzir, acumular, transmitir e disseminar conhecimentos para formar novos especialistas. Este é o caso na região do Alto Rio Negro. Por outro lado, a universidade pode oportunizar a pensar o pensamento indígena, na medida em que os mecanismos e métodos científicos podem servir como instrumentos para compreender as cosmologias e produzir os conceitos propriamente 'nativos', possibilitando um diálogo simétrico entre os modelos de conhecimento. Mas para isso acontecer é necessário que nós indígenas tenhamos bastante consciência de que o simples ingresso na universidade não assegura colocar nossa epistemologia e nossas ideias em pauta na sala de aula e nos programas de pós-graduação (Fontes, 2019, p. 223).

O lento cumprimento do direito dos aprendizes e coletivos indígenas ao ensino superior, portanto, ao mesmo tempo pede e enseja a adoção de reajustes pedagógicos, gerenciais e epistemológicos dos modelos universitários. As lições extraídas das experiências concretas propiciam bases para essa reorientação, num processo que pode ser, em si mesmo, uma contribuição dos pensadores indígenas para a mudança das formas de relações sociais e culturais na sociedade em geral. A viabilização desse projeto exige a valorização - ao invés da domesticação - do que Fontes chamou de atitude "transgressiva" por parte dos estudantes indígenas que ingressam na universidade, visando à formulação de traduções e enunciados autodirigidos do pensamento nativo ${ }^{28}$.

Recebido em 27 de junho de 2021 Aprovado em 21 de setembro de 2021

\section{Notas}

1 Título e resumo vertidos à língua yẽgatu por Maria do Rosário Piloto Martins.

2 Título e resumo vertidos à língua tukano por Mirlene Costa Gentil.

3 Título e resumo vertidos à língua baniwa por Eliane Claudio Guilherme.

4 Embora a Constituição de 1988 afirme a educação como "direito de todos e dever do Estado e da família" (art. 205), ela detalha as implicações desse dever somente quanto aos aspectos de garantia da "educação básica obrigatória e gratuita de 4 (quatro) a 17 (dezessete) anos de idade". Para os "níveis mais elevados de educação, pesquisa e criação artística”, a lei prescreve (seguindo a fórmula da Declaração da ONU) que sejam ocupados "de acordo com a capacidade de cada pessoa" - ou seja, por critérios não discriminatórios, mas admitindo 
O Brasil Respeita o Direito dos Povos Indígenas à Educação Superior?

sistemas de restrição de vagas, portanto não obrigando legalmente o Estado a assegurar a oferta geral de oportunidades de ensino superior.

5 Deslocando, por exemplo, o debate sobre as políticas de ação afirmativa - cujo desenho, baseado na substituição da chamada "discriminação meritocrática" dos procedimentos de admissão por uma discriminação "positiva", ainda responde ao paradigma de um sistema com quantidades artificialmente limitadas de vagas, tornadas acessíveis (por um critério ou outro) a poucos selecionados.

6 Junto com o que é conhecido localmente como assessoria: parceria com associações comunitárias, escolas e outros grupos semelhantes para atividades de formação e intervenção conjunta (no nosso caso, em torno das práticas escolares e política educacional). Durante as viagens de 2018-2020, atividades de assessoria incluíram oficinas de aprendizagem com grupos docentes, estudantes e outras pessoas das comunidades; apoio à elaboração coletiva de documentos escritos de interesse destas; e ações conjuntas para publicação de pesquisas de estudantes. No interior desse campo de colaboração recíproca também são colhidas informações, inclusive algumas das utilizadas neste artigo.

7 Ammon (2019) atesta algumas dessas dificuldades pela perspectiva de funcionários e professores da Universidade de Free State, em Bloemfontein, na África do Sul.

8 Hoje, mais de 90 associações indígenas de base na região compõem a Federação das Organizações Indígenas do Rio Negro (FOIRN).

9 Comunicação pessoal, 4 fev. 2021.

10 Marginalmente, também houve iniciativas para criar "universidades indígenas". Exemplos são a experiência da Universidade da Floresta, no Acre, cujo projeto ambiciosamente contra-hegemônico teve início em 2006, mas sofreu progressiva desfiguração, sendo absorvido como câmpus avançado da Universidade Federal do Acre (Albuquerque, 2015); e a Universidade Indígena do Rio Negro, aludida a seguir (McCowan, 2016).

$11 \mathrm{O}$ número de indígenas matriculados no ensino superior no Brasil cresceu $52,5 \%$ entre 2015 (quando eram cerca de 32 mil alunos) e 2016 (quando chegaram a 49 mil). Em 2017, o número aproximado era de 56,7 mil. Em 2019, o Censo da Educação Superior registrou 56.257 matrículas de alunos indígenas, representando $1,5 \%$ das matrículas nacionais (no mesmo ano, a taxa bruta de matrícula em nível superior no Brasil era de 37,4\%, cf. INEP, 2020). Mas o estado do Amazonas, com população indígena em torno de 170 mil pessoas, tinha apenas 3.803 matrículas indígenas no ensino superior em 2019, enquanto o estado de São Paulo, com uma população indígena quatro vezes menor (cerca de 42 mil), em 2019 tinha o dobro: 7.657. As cifras vêm de INEP (2021), Estudantes... (2018) e Tokarina (2019). Estima-se que haja atualmente cerca de 1,3 milhão de pessoas indígenas no País (Corte..., 2021). No Censo de 2010, contaram-se 896,9 mil pessoas indígenas.

12 Agradecemos a Marta Azevedo por trazer à nossa atenção estas cruciais observações.

13 A informação consta do documento Relatório Formação Avançada Indígena do Rio Negro - 2013 (FOIRN / Instituto Socioambiental), conforme citado em CGEE (2014, p. 5).

14 Cf. nota 10 , acima. 
15 A expressão é de Carneiro da Cunha (2009, p. 13) falando sobre a experiência da Universidade da Floresta, projeto no qual teve grande envolvimento.

16 Para mais informações sobre o acesso dos indígenas aos cursos de pósgraduação no Brasil, cf. Fiori et al. (2017).

17 Os dados atribuem esse curso ao Instituto Federal de Educação do Amazonas, IFAM, mas este só oferece cursos de nível médio e técnico. No âmbito de uma parceria institucional, o IFAM emprestou suas excelentes instalações para a realização da Licenciatura Formação de Professores Indígenas da UFAM entre 2015 e 2021, como se verá; e é possível que esse arranjo local tenha gerado o registro oficial impreciso.

18 Apesar do nome, que levaria a associá-lo ao modelo de licenciaturas interculturais indígenas acima descrito, a informação disponível sobre esse curso no site da universidade retrata um curso de formação de professores bastante regular exceto pela ênfase em legislação escolar indígena, gestão escolar participativa e diversidade cultural, mas sem manter semelhanças com os princípios de interculturalidade e forte governança comunitária contidos naquele modelo.

19 Mais recentemente, passou a funcionar um polo Yanomami em Santa Isabel (Sem Aula..., 2019).

20 Em acordo com os termos da política linguística definida em conjunto com as comunidades, os documentos do curso e aparições dos professores na mídia afirmavam (talvez como forma de reiterar uma legitimidade epistemológica simétrica às línguas nativas) que o tukano, o baniwa e o yẽgatu eram "as línguas de instrução" da licenciatura, embora os professores fossem virtualmente todos brancos e não falantes dessas línguas.

21 O curso possui um canal no YouTube exibindo algumas das produções audiovisuais dos alunos, em https://www.youtube.com/user/licenciaturaindigena/.

22 Aderindo à rica interpretação que Torres (2011) dá aos quatro indicadores de Tomasevski, as perguntas enfocaram autoestima, reconhecimento, diversão e realização como aspectos da dimensão da Aceitabilidade.

23 Gersem José dos Santos Luciano, do povo Baniwa, natural de São Gabriel e ex-secretário de Educação da cidade, aliou uma notável trajetória acadêmica de filósofo e antropólogo (Luciano, 2006; 2011) ao sólido percurso como liderança no movimento indígena, influenciando as políticas nacionais de escolarização indígena e manifestando-se, também na qualidade de professor e intelectual, pelo fortalecimento de um pensamento indígena original, enraizado nas tradições e transgredindo a colonialidade.

24 Gallois (2013) alerta que corpos de conhecimento distintos têm seus próprios regimes de produção, aprendizagem e circulação, muitas vezes incompatíveis com os procedimentos escolares cristalizados; e Marqui e Beltrame (2017) exemplificam como a escolarização de práticas e conteúdos indígenas pode levá-los a uma fronteira onde se tornam, por assim dizer, menos indígenas e mais escolares.

25 Ambas as dificuldades também foram encontradas no caso examinado por Ammon (2019).

26 Para mais informações sobre a expansão da privatização no ensino superior brasileiro, ver por exemplo Carvalho (2013).

27 Em gerações anteriores, muitos dos primeiros indígenas das comunidades rionegrinas que estudaram antes de haver escolas primárias suficientes nas 
O Brasil Respeita o Direito dos Povos Indígenas à Educação Superior?

comunidades o fizeram justamente saindo de casa, às vezes muito jovens, e vivendo por alguns anos em locais como Iauaretê, São Gabriel, Manaus ou Colômbia, onde obtinham instrução escolar, trabalhavam, compravam objetos e aprendiam português, yẽgatu ou espanhol, além dos costumes dos não-indígenas. Para uma narrativa exemplar, cf. Fontes (2019, p. 22-24).

28 Agradecimentos: este texto integra uma série de artigos resultantes do projeto de pesquisa "Educação escolar indígena: inovação, saberes aprendidos e ofertas de ensino superior" (Ceunir-Feusp, 2017-2020, financiado pelo CNPq e Fapesp). Os/as pesquisadores/as Elydimara Durso dos Reis, Márcia Regina Guerreiro Zamboni, Humberto Borges Sanjinez, Marta Maria do Amaral Azevedo e Fabio de Oliveira Nogueira da Silva também participaram da coleta e discussão das informações; porém o grupo de autores é o único responsável pela forma e conteúdo final. Agradecemos a Cleunice Alberta Camico Jacinto, Orlando Garcia Gonçalves, José Apolinário Venceslau e Mirlene Costa Gentil por suas valiosas reflexões.

\section{Referências}

ABBONIZIO, Aline C. O. Educação escolar indígena como inovação educacional: a escola e as aspirações de futuro das comunidades. 2013. $193 \mathrm{f}$. Tese (Doutorado em Educação) - Faculdade de Educação, Universidade de São Paulo, São Paulo, 2013.

ALBUQUERQUE, Ramayana A. Um estudo sobre a criação e implementação da Universidade da Floresta no Acre: uma discussão sobre conhecimentos tradicionais. 2015. 134 f. Dissertação (Mestrado em Educação) - Faculdade de Educação, Universidade de Campinas, Campinas, 2015.

AMARAL, Wagner R.; FRAGA, Letícia; RODRIGUES, Isabel C. (Org.). Universidade para indígenas: a experiência do Paraná. Rio de Janeiro: Flacso; LPP-UERJ, 2016. $186 \mathrm{p}$.

AMMON, Linnéa. Decolonizing the university curriculum in South Africa: a case study of the University of the Free State. 2019. 54 f. Tese (Master Degree) Linaeus University, Växjö, 2019.

AZEVEDO, Marta M.A.; SOUZA, Laeticia R. Projeto Educação Indígena: o perfil da educação básica indígena no Brasil e em estados e municípios selecionados. 2020. $68 \mathrm{f}$.

BALLESTRIN, Luciana. América Latina e o giro decolonial. Revista Brasileira de Ciência Política, Brasília, n. 11, p. 89-117, maio/ago. 2013.

CABALZAR, Aloísio; RICARDO, Carlos A. Povos indígenas do Rio Negro: uma introdução à diversidade socioambiental do noroeste da Amazônia brasileira. São Paulo: Instituto Socioambiental; São Gabriel da Cachoeira: Federação das Organizações Indígenas do Rio Negro, 2006. 128 f.

CARNEIRO DA CUNHA, Maria M. L. Cultura com aspas e outros ensaios. São Paulo: Cosac \& Naify, 2009. 436 f.

CARVALHO, Cristina H. A. A mercantilização da educação superior brasileira e as estratégias de mercado das instituições lucrativas. Revista Brasileira de Educação, Rio de Janeiro, v. 18, n. 54, p. 761-776, 2013.

CGEE. Centro de Gestão e Estudos Estratégicos. Apoio à criação de uma instituição de ensino superior indígena. Brasília: CGEE, 2014. 312 f. 
CORTE no Censo 2021 ameaça políticas públicas para povos indígenas e tradicionais. Notícias Socioambientais, 23 abr. 2021. Disponível em: https://www. socioambiental.org/pt-br/noticias-socioambientais/corte-no-censo-2021ameaca-politicas-publicas-para-povos-indigenas-e-tradicionais. Acesso em: 23 ago. 2021.

CURSO de licenciatura intercultural da UFAM (políticas educacionais e desenvolvimento sustentável). Ensino Superior Indígena - Mapeamento de Controvérsias, Manaus, 2021. Disponível em: https://ensinosuperiorindigena.wordpress.com/atores/nao-humanos/li-ufaml/. Acesso em: 14 fev. 2021.

ESTUDANTES indígenas ganham as universidades. Ministério da Justiça e Segurança Pública, Brasília, 21 mar. 2018. Disponível em: https://www.justica. gov.br/news/estudantes-indigenas-ganham-as-universidades\#: :text=A\%20 mudan\%C3\%A7a\%20no\%20tecido\%20social,passando\%20de\%2032.147\%20 para\%2049.026. Acesso em: 14 fev. 2021.

FIORI, Ana L. et al. O tempo e o vento: notas sobre a arte de burocratizar políticas de cotas na USP. Revista de Antropologia, v. 60, n. 1, p. 55-83, 2017.

FONTES, Francineia Bitencourt. Hiipana, Eeno Hiepolekoa: construindo um pensamento antropológico a partir da mitologia baniwa e de suas transformações. 2019. 225 f. Dissertação (Mestrado em Antropologia Social) - Museu Nacional, Universidade Federal do Rio de Janeiro, 2019.

GALLOIS, Dominique T. A escola como problema: algumas posições. In: CARNEIRO DA CUNHA, Manuela; CESARINO, Pedro N. (Org.). Políticas culturais e povos indígenas. São Paulo: Ed. Unesp, 2013. P. 509-517.

GHANEM, Elie. Que avaliação vale na educação escolar? In: LUCE, Maria B.; MEDEIROS, Isabel L.P. (Org.). Gestão escolar democrática: concepções e vivências. Porto Alegre: UFRGS, 2006.

GHANEM, Elie; ABBONIZIO, Aline. A escola e as aspirações de futuro das comunidades. Tellus, v. 12, n. 23, p. 147-161, jul./dez. 2012.

IBGE. Instituto Brasileiro de Geografia e Estatística. Cidades e estados: São Gabriel da Cachoeira. 2020. Disponível em: https://cidades.ibge.gov.br/brasil/am/ sao-gabriel-da-cachoeira/pesquisa/23/22107. Acesso em: 14 fev. 2021.

INEP. Instituto Nacional de Estudos e Pesquisas Educacionais Anísio Teixeira. Sinopse Estatística da Educação Básica 2018. Brasília: INEP, 2019. Disponível em: http://portal.inep.gov.br/sinopses-estatisticas-da-educacao-basica. Acesso em: 10 maio 2019.

INEP. Instituto Nacional de Estudos e Pesquisas Educacionais Anísio Teixeira. Censo da Educação Superior 2019: divulgação dos resultados. Brasília: INEP, 2020. Disponível em: https://download.inep.gov.br/educacao_superior/censo_superior/documentos/2020/Apresentacao_Censo_da_Educacao_Superior_2019.pdf. Acesso em: 23 ago. 2021.

INEP. Instituto Nacional de Estudos e Pesquisas Educacionais Anísio Teixeira. Censo da educação superior. Brasília, 2021. Disponível em: https://www.gov. $\mathrm{br} / \mathrm{inep} / \mathrm{pt}$-br/areas-de-atuacao/pesquisas-estatisticas-e-indicadores/censoda-educacao-superior/resultados. Acesso em: 14 fev. 2021.

LASMAR, Cristiane; GORDON, Cesar. 2015. Um antropólogo da civilização amazônica: entrevista com Stephen Hugh-Jones. Sociol. Antropol., v. 5, n. 3, p. 627-658, 2015.

LIMA, Antonio C. S. Cenários da educação superior de indígenas no Brasil, 2004-2008: as bases e diálogos do Projeto Trilhas de Conhecimentos. In: LIMA, 
O Brasil Respeita o Direito dos Povos Indígenas à Educação Superior?

Antonio C.S.; BARROSO, Maria M. (Org.). Povos indígenas e universidade no Brasil: contextos e perspectivas, 2004-2008. Rio de Janeiro: E-papers, 2013. P. 15-44.

LIMA, Antonio C. S.; BARROSO, Maria M. A presença indígena na construção de uma educação superior universal, diferenciada e de qualidade. In: LIMA, Antonio C.S.; BARROSO, Maria M. (Org.). Povos indígenas e universidade no Brasil: contextos e perspectivas, 2004-2008. Rio de Janeiro: E-papers, 2013. P. 45-77.

LUCIANO, Gersem José dos Santos. "Projeto é como branco trabalha; as lideranças que se virem para aprender e nos ensinar": experiências dos povos indígenas do alto rio Negro. 2006. 162 f. Dissertação (Mestrado em Antropologia Social) - Universidade de Brasília, Brasília, 2006.

LUCIANO, Gersem José dos Santos. Educação para manejo e domesticação do mundo entre a escola ideal e a escola real: os dilemas da educação escolar indígena no Alto Rio Negro. 2011. 370 f. Tese (Doutorado em Antropologia) - Universidade de Brasília, Brasília, 2011.

MARQUI, Amanda Rodrigues; BELTRAME, Camila Boldrin. As experiências Xikrin e Baniwa com os conhecimentos tradicionais nas escolas. Univ. Humanist., n. 84, p. 239-261, 2017.

MATO, Daniel (Coord.). Educación superior y pueblos indígenas en América Latina: contextos y experiencias. Sáens Peña: Universidad Nacional de Tres de Febrero, 2015. $248 \mathrm{f}$.

MCCOWAN, Tristan. A base conceitual do direito universal à educação superior. Conjectura: Filos. Educ., Caxias do Sul, v. 20, n. especial, p. 155-182, 2015. Disponível em: http://www.ucs.br/etc/revistas/index.php/conjectura/article/ view/3655. Acesso em: 02 jun. 2021.

MCCOWAN, Tristan. Forging radical alternatives in higher education: the case of Brazil. Other Education: The Journal of Educational Alternatives, v. 5, n. 2, p. 196-220, 2016.

PELLEGRINI, Diana. Saberes escolares e comunidade indígena: inovação educacional entre os Baniwa do alto rio Negro. In: GHANEM, Elie. G. G.; NEIRA, Marcos. G. (Org.). Educação e diversidade cultural no Brasil: ensaios e práticas. Araraquara: Junqueira \& Marin Editores, 2014. P. 245-272.

PELLEGRINI, Diana et al. Os direitos dos povos indígenas quanto à sua educação escolar: parecer científico. São Gabriel da Cachoeira, 2019. 7 f.

PELLEGRINI, Diana; GHANEM, Elie; GÓES NETO, Antônio F. Criação da Escola Indígena Baniwa e Koripako Pamáali: condições legais e administrativas: parecer de assessoria técnica. Manaus; São Paulo, 2020. 9 f.

RIBEIRO, Berta. Os índios das águas pretas: modo de produção e equipamento produtivo. São Paulo: Companhia das Letras; Edusp, 1995. 270 f.

SCHOFER, Evan; MEYER, John W. The Worldwide Expansion of Higher Education in the Twentieth Century. American Sociological Review, v. 70, n. 6, p. 898920, 2005.

SEM aula e sem diploma. Notícias Socioambientais, 7 nov. 2019. Disponível em: https://www.socioambiental.org/pt-br/noticias-socioambientais/sem-aula-esem-diploma. Acesso em: 14 fev. 2021.

SOUZA, Hellen de. Educação superior para indígenas no Brasil: mapeamento provisório. Tangará da Serra: Fundação Universidade do Estado de Mato Grosso; Instituto para la Educación Superior en América Latina y el Caribe; UNESCO, 2003. 
TOKARINA, Mariana. Ingresso de indígenas em faculdades é nove vezes maior do que em 2010. Agência Brasil, Brasília, Empresa Brasileira de Comunicação, 19 abr. 2019. Disponível em: https://agenciabrasil.ebc.com.br/educacao/noticia/2019-04/ingresso-de-indigenas-em-faculdades-e-nove-vezes-maior-doque-em-2010. Acesso em: 14 fev. 2021.

TOMASEVSKI, Katarina. Indicadores del derecho a la educación. Revista Instituto Interamericano de Derechos Humanos, v. 40, n. 96, p. 341-388, 2004.

TORRES, Rosa María. Las 4 A como criterios para identificar "buenas prácticas" en educación. 2011. Disponível em: https://otra-educacion.blogspot. com/2011/10/las-4a-como-criterios-para-identificar.html. Acesso em: 19 jan. 2021.

UFSCAR. Universidade Federal de São Carlos. UFSCar divulga convocação para as provas do Vestibular Indígena 2019. São Carlos, 11 jan. 2019. Disponível em: https://www.saci.ufscar.br/servico_release?id=108740\&pro=3. Acesso em: 14 fev. 2021.

VIEIRA, Luana R. Escola indígena diferenciada: a experiência Yanomami no Médio Rio Negro. 2018. 157 f. Dissertação (Mestrado em Educação) - Faculdade de Educação, Universidade de São Paulo, São Paulo, 2018.

WALSH, Catherine. Interculturalidad y (de)colonialidad: perspectivas críticas y políticas. Visão Global, Joaçaba, v. 15, n. 1-2, p. 61-74, jan./dez. 2012.

Diana de Paula Pellegrini é pesquisadora e educadora desde 2012, na Linha de Investigações em Educação Escolar Indígena do Ceunir.

ORCID: https://orcid.org/0000-0002-1014-9082

E-mail: diana.pellegrini@gmail.com

Elie Ghanem é professor de Sociologia de Educação na Faculdade de Educação da Universidade de São Paulo (USP), onde coordena o Centro Universitário de Investigações em Inovação, Reforma e Mudança Educacional (Ceunir).

ORCID: https://orcid.org/0000-0001-9440-3940

E-mail: elie@usp.br

Antônio Fernandes Góes Neto é pesquisador do Centro Universitário de Investigações em Inovação, Reforma e Mudança Educacional (Ceunir) e estudante de doutorado na Faculdade de Educação da USP. Como linguista, realiza trabalhos de cunho etnográfico no alto rio Negro desde 2012.

ORCID: https://orcid.org/0000-0002-5312-4168

E-mail: antonio.fernandes.neto@usp.br

Editor-responsável: Luís Armando Gandin

Este é um artigo de acesso aberto distribuído sob os termos de uma Licença Creative Commons Atribuição 4.0 Internacional. Disponível em: <http:// creativecommons.org/licenses/by/4.0>. 